Case Blog

ISSN: $\mathbf{2 4 5 5 - 8 7 0 2}$

\title{
Posttraumatic Anosmia Secondary to Cranial Base Contusion
}

\author{
Nobuko Makino ${ }^{1}$ and Shinji Makino ${ }^{2 *}$ \\ ${ }^{1}$ Division of General Medicine, Center for Community Medicine, Jichi Medical University, Japan \\ ${ }^{2}$ Department of Ophthalmology, Jichi Medical University, Japan
}

*Corresponding author: Shinji Makino, MD, Shimotsuke, 3311-1 Yakushiji, Tochigi 329-0498, Japan, Tel: +81-285-58-7382; Fax: +81-285-44-8365; E-mail: makichan@jichi.ac.jp

\section{Received: July 20, 2014; Accepted: July 22, 2014; Published: July 24, 2014}

Head trauma is a common cause of anosmia; however, the diagnosis is typically late, owing to greater attention being given to the more life-threatening sequelae of the injury. Studies have cited olfactory dysfunction as occurring in approximately $30 \%$ of all head traumas [1].

A 19-year-old woman presented with olfactory disturbance after suffering a cranial base fracture 2 months previously in a traffic accident. Examination by T\&T olfactogram revealed that she had the condition of total anosmia. Brain magnetic resonance imaging (MRI) showed abnormal intensity due to cerebral contusion bilaterally in the orbitofrontal cortex, predominantly on the right side (Figure 1, white arrow; Figure 2, arrows; Figure 3, arrows). In contrast, definite laterality was not detected at the olfactory tracts (Figure 1, yellow arrows). From the above findings, we speculated that the anosmia in this patient may have been caused mainly by orbitofrontal cortex damage.

MRI has demonstrated abnormalities in patients with

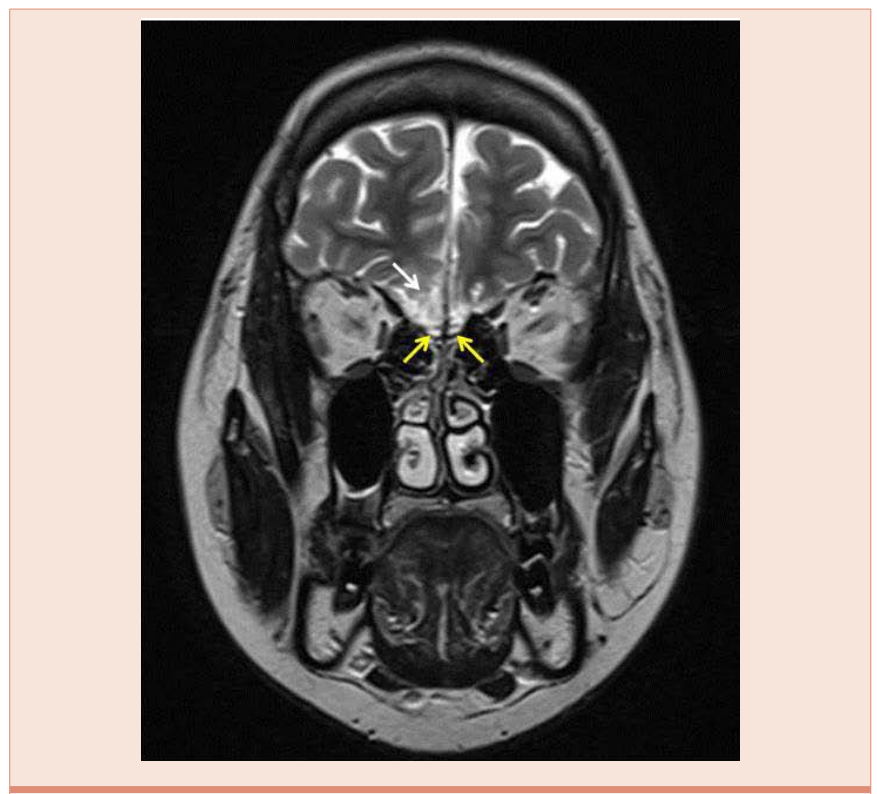

Figure 1: MRI: T2-weighted coronal image.

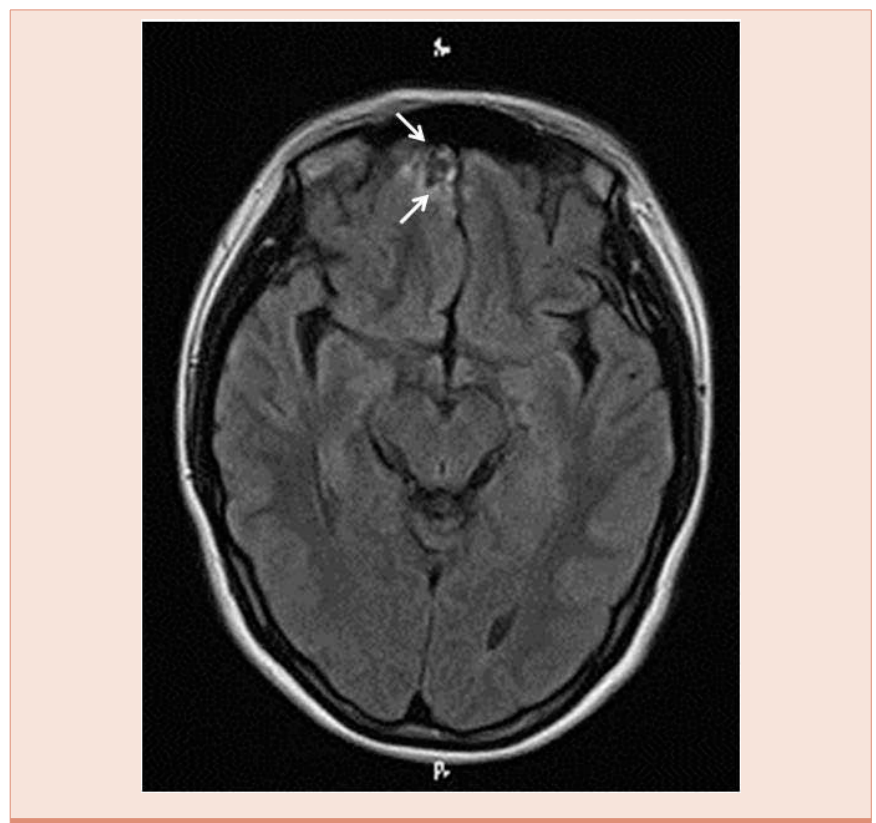

Figure 2: MRI: axial FLAIR (fluid-attenuated inversion recovery) image.

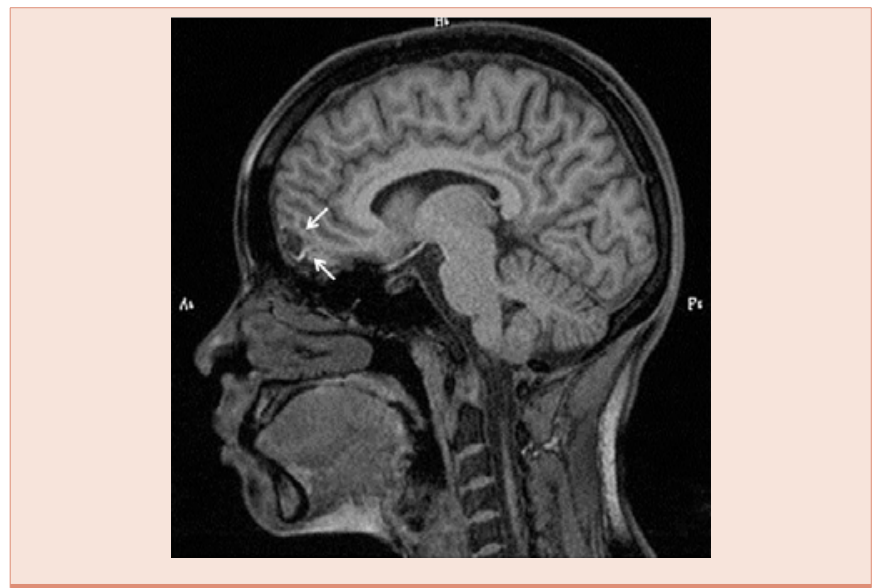

Figure 3: MRI: T2-weighted sagittal image. 
posttraumatic olfactory dysfunction at a very high rate $(88 \%)$, predominantly in the olfactory bulbs and tracts and the inferior frontal lobes [2]. The site-specific incidence of abnormalities in the brain MRIs of patients with posttraumatic anosmia has been reported as follows: the frontal lobe was the most injured site (62\%) followed by the olfactory bulb (48\%), olfactory nerve (37\%), temporal lobe (13\%), and parietal lobe (10\%) [3]. We propose that conventional MRI, performed both at the time of injury and during follow-up, particularly in patients with frontal lesions, may alert the clinician to the possibility of olfactory dysfunction, thus allowing for early consultation with an otolaryngologist and early use of objective smell testing.

\section{References}

1. Yousem DM, Oguz KK, Li C (2001) Imaging of the olfactory system. Semin Ultrasound CT MRI 22: 456-472.

2. Yousem DM, Geckle RJ, Bilker WB, McKeown DA, Doty RL (1996) Posttraumatic olfactory dysfunction: MR and clinical evaluation. Am J Neuroradiol 17: 1171-1179.

3. Atighechi S, Zolfaghari A, Baradaranfar M, Dadgarnia M (2013) Estimation of sensitivity and specificity of brain magnetic resonance imaging and single photon emission computed tomography in the diagnosis of olfactory dysfunction after head traumas. Am J Rhinol Allergy 27: 403-406. 